\title{
Call centre agents' emotional intelligence as predicators of their exhaustion and professional efficacy: The moderating effect of meaningfulness
}

\begin{tabular}{|c|c|}
\hline \multicolumn{2}{|c|}{$\begin{array}{l}\text { Author: } \\
\text { Nisha Harry }{ }^{1} \text { (D) }\end{array}$} \\
\hline \multicolumn{2}{|c|}{$\begin{array}{l}\text { Affiliation: } \\
{ }^{1} \text { Department of Industrial and } \\
\text { Organisational Psychology, } \\
\text { University of South Africa, } \\
\text { Pretoria, South Africa }\end{array}$} \\
\hline \multicolumn{2}{|c|}{$\begin{array}{l}\text { Corresponding author: } \\
\text { Nisha Harry, } \\
\text { harryn@unisa.ac.za }\end{array}$} \\
\hline \multicolumn{2}{|c|}{$\begin{array}{l}\text { Research Project Registration: } \\
\text { Project Number: } 2016 \text { _ } \\
\text { CEMS/IOP_060 staff number } \\
90163540\end{array}$} \\
\hline \multicolumn{2}{|c|}{$\begin{array}{l}\text { Dates: } \\
\text { Received: } 25 \text { June } 2020 \\
\text { Accepted: } 23 \text { Nov. } 2020 \\
\text { Published: } 16 \text { Mar. } 2021\end{array}$} \\
\hline \multicolumn{2}{|c|}{$\begin{array}{l}\text { How to cite this article: } \\
\text { Harry, N. (2021). Call centre } \\
\text { agents' emotional intelligence } \\
\text { as predicators of their } \\
\text { exhaustion and professional } \\
\text { efficacy: The moderating } \\
\text { effect of meaningfulness. } \\
\text { SA Journal of Industrial } \\
\text { Psychology/SA Tydskrif vir } \\
\text { Bedryfsielkunde, } 47(0), \text { a1819. } \\
\text { https://doi.org/10.4102/sajip. } \\
\text { v47i0.1819 }\end{array}$} \\
\hline \multicolumn{2}{|c|}{$\begin{array}{l}\text { Copyright: } \\
\text { (C) 2021. The Authors. } \\
\text { Licensee: AOSIS. This work } \\
\text { is licensed under the } \\
\text { Creative Commons } \\
\text { Attribution License. }\end{array}$} \\
\hline \multicolumn{2}{|l|}{ Read online: } \\
\hline 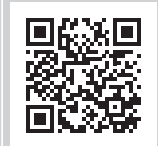 & $\begin{array}{l}\text { Scan this QR } \\
\text { code with your } \\
\text { smart phone or } \\
\text { mobile device } \\
\text { to read online. }\end{array}$ \\
\hline
\end{tabular}

Orientation: Call centres in a digital work environment in Africa typically require high levels of sustained interpersonal contact with customers, which lead to exhaustion and call centre agent withdrawal.

Research purpose: This study investigates the interaction effects between call centre agents' emotional intelligence and their sense of meaningfulness (as moderating mechanism) in predicting their exhaustion and professional efficacy.

Motivation for the study: Human resource practitioners need deeper understanding/insight of meaningfulness as a moderating mechanism in the link between call centre agents' emotional intelligence, levels of exhaustion and sense of professional efficacy. Such knowledge is important for informing wellness programmes for call centre agents.

Research approach/design and method: A quantitative cross-sectional survey approach was followed. A non-probability sample of $(N=409)$ of permanently employed call centre employees in Lagos, Nigeria, and Johannesburg and Durban, South Africa participated in this study.

Main findings: Moderated regression analysis showed that call centre agents' sense of meaningfulness and the ability to perceive and manage others' emotions significantly moderates exhaustion and professional efficacy.

Practical/managerial implications: Overall the results provide evidence of the importance of considering call centre agents' sense of meaningfulness, perceptions of emotions and managing others' emotions as a resource for supporting their exhaustion levels as well as professional efficacy in dealing with stress.

Contribution/value-add: The research will add to the interventions needed to be developed to strengthen the relationship between sense of meaningfulness, perceptions of emotions and managing others' emotions and exhaustion and professional efficacy in the call centre industry within Lagos, Nigeria, and Johannesburg and Durban, South Africa.

Keywords: exhaustion; sense of meaningfulness; professional efficacy; emotional intelligence; call centre agents.

\section{Introduction}

The call centre work that typifies the digital revolution requires high levels of sustained interpersonal interaction with customers, which has led to high levels of exhaustion and employee withdrawal (Anwar \& Graham, 2019). Call centres in Africa have become notorious for having the highest attrition rate of any industry (Frost \& Sullivan, 2018). The levels of exhaustion stem from requiring to deal with challenging and frustrated customers (Shkoler \& Tziner, 2017). The emotional outbursts accompanied by irritability and anger are considered the main reasons for declining performance (Frost \& Sullivan, 2018). Exhaustion and fatigue are evident in these work environments that lead to a decreased level of organisational commitment (Shkoler \& Tziner, 2017). Changes in call centre agents' behaviour include a reduced sense of professional efficacy which is characterised by low morale and an inability to cope (Frost \& Sullivan, 2018).

The modern consumers are no longer willing to accept insufficient customer service as the future of these work environments' demand quick responses to queries, resulting in customer hostility and abuse if customers' demands are not being met (Frost \& Sullivan, 2018). In research, it is proven that promoting the adoption of proactive and effective coping involves a sense of utilising 
and perceiving emotions, in the relationship with exhaustion and depersonalisation, when dealing with stress (Por, Barriball, \& Fitzpatrick, 2011). The emotional intelligence model dictates the importance of individual differences in the way people process emotions, in particular how they identify their own emotions, understand and regulate these emotions and those of others (Ma \& Liu, 2019). In research, exhaustion has been explained as demanding and emotionally charged interactions, the emotional nature of interpersonal encounters serve as predictors of exhaustion and reduced personal accomplishment (Adil \& Baig, 2018; Szczygiel \& Bazinska, 2013).

This study investigates the interaction effects between call centre agents' emotional intelligence and their sense of meaningfulness (as moderating mechanism) in predicting their exhaustion and professional efficacy. Theoretically, there is ground to consider the interaction effects on meaningfulness in dealing with job demands that cause exhaustion and depersonalisation as little is known in this area.

\section{Theoretical background \\ Emotional intelligence and exhaustion}

Emotional intelligence has become a key factor in well-being, in highlighting the importance of intellectual functioning and information processing (Salovey \& Mayer, 1990). The definition of emotional intelligence in research is well documented as the ability to recognise one's own and others' emotions, to differentiate between feelings and use emotional information which guides thinking, behaviour and performance (Boyatzis, 2009; Goleman, 1995; Joseph \& Newman, 2010; Mayer \& Salovey, 1997; Salovey \& Mayer, 1990).

The present study investigates the role of emotional intelligence and exhaustion within the job demands-resource model (JD-R), regarded as a heuristic model based on the premise of two sets of working conditions that may produce health impairment and motivation (Adil \& Baig, 2018). The health hindrance (distress) is known as the reduced energy process, and this represents the imbalance between high job demands and low job resources and the motivational process indicates that low job resources prevent the ability to cope, whilst high job demands lead to reduced accomplishments (Adil \& Baig, 2018). Emotional intelligence abilities function as important psychological resources, such as perceiving and managing emotions can compensate for excessive demands (Adil \& Baig, 2018). Psychological resources are depleted when the emotional nature of work in call centres does have direct outcomes on exhaustion and personal accomplishment (Harry, 2015).

Research proves that perceiving, managing, monitoring and utilising own and others' emotions are deemed positive in people coping better in life when in control of their emotions (Zerach \& Levin, 2018). In order for individuals to regulate emotions, the effectiveness of perceiving, utilising and managing emotions favours the intellectual and emotional development of individuals. Emotional intelligence contributes to subjects understanding and performing their actions with greater efficiency (Hanafi, 2016; Salovey \& Mayer, 1990). Individuals can effectively deal with emotions from within as well as from others and in turn manage this emotional information by becoming self-aware and having the ability to perceive emotions. Self-management results are the ability to manage emotions and stimuli from the environment (Hanafi, 2016; Salovey \& Mayer, 1990).

Research also indicates that emotional intensity is positively related to emotional exhaustion and depersonalisation, suggesting that occupational burnout is mainly caused by stressful interaction with clients (Teinlin et al., 2017). The concept of positive affectivity has received much attention from various researchers all suggesting that positive affectivity is negatively related to emotional exhaustion. Emotional intelligence should be approached from an ability as well as trait models (Zerach \& Levin, 2018). Ability models capture employees' ability to use, and the ability of what a person is capable of doing. The construct of trait emotional intelligence focuses on a constellation of emotions, namely the extent to which employees identify, understand and regulate one's own and others' emotions (Hanafi, 2016; Salovey \& Mayer, 1990). Results in research reveal that trait emotional intelligence especially within call centres in Africa is useful in identifying individual differences and more likely to appraise stressful situations and be able to cope in such situations (Harry, 2015).

Within the JD-R model, specific work characteristics/ demands such as call centres do associate with burnout/ exhaustion that necessitates emotional labour, which is characterised by the constant pressure to meet demands, resulting in psychological strain (Adil \& Baig, 2018). These demands require sustained psychological effort that is associated with high work pressure. The emotional nature of work in call centres does have direct outcomes on burnout dimensions of exhaustion and personal accomplishment, as it affects individual traits such as emotional intelligence and affective states of emotions experienced at work (Harry, 2015). In research conducted in call centres what has been established is negative affectivity was significantly associated with higher levels of emotional exhaustion (Szczygiel \& Bazinska, 2013). Emotional exhaustion is caused by work pressure and a loss of energy. Empirical research indicates burnout to be caused by many organisational variables, amongst which it is important to highlight the client-related stressor especially given the changes that are taking place in call centre in Lagos, Nigeria, and Johannesburg and Durban, South Africa (Schäfer, Becker, King, Horsch, \& Michael, 2019).

Research into the third dimension of burnout shows that the professional efficacy points to a lack of personal fulfilment, which results in employees leaving the organisation, a characteristic of many call centres in Africa (Anwar \& Graham, 2019). On the other hand, having a sense of efficacy 
does include aspects that a worker would consider as being meaningful and worthwhile: accomplishments and abilities can serve as a buffer to emotional exhaustion, as previously mentioned (Anwar \& Graham, 2019).

Researchers have reviewed the social perspective of exhaustion in which people utilise the interpersonal relation by responding and perceiving others through the process of motivation and emotions, especially when coping with emotional arousal. The importance of managing others' emotions, perceiving others' emotions and understanding emotions of customers are important internal resources for dealing with exhaustion and depersonalisation within call centres in Africa (Schäfer et al., 2019).

\section{Moderating effect of meaningfulness}

The sense of meaningfulness, regarded as a motivational component is important as a moderating mechanism that explains the use of emotional intelligence resources such as managing, utilising and perceiving emotions in call centre work (Richardson \& Ratner, 2006; Rohani, Abedi, Sundberg, \& Langius-Eklöf, 2015). This is based on the conditional interaction with work-related outcomes, constituting the extent of belief that things in life are worthwhile and there is a good reason for any individual to care about what happens and wishes to cope with all indicators of health and well-being (Richardson \& Ratner, 2006; Rohani et al., 2015). Authors have reported in the previous work on the moderating effects of the sense of meaningfulness by analysing the degree of moderation with different variables such as subjective perceptions of psychological health and wellbeing and experience with stress symptoms (Richardson \& Ratner, 2006; Rohani et al., 2015).

Research in Africa regarding the moderating effects of the sense of meaningfulness and exhaustion and depersonalisation has been established as having a negative effect. This indicates that the sense of meaningfulness as a protective function modifies the negative effects of stress (Johnston et al., 2013). In other research conducted, sense of meaningfulness had negative associations with exhaustion and depersonalisation. This implies individuals will start to assess the availability of resources to increase feeling of control (Eriksson \& Mittelmark, 2017). The sense of coherence can be better in predicting perceptions and managing emotions, based on areas of presumed overlapping such as perceptions of external and emotional stimuli, and making sense of these stimuli. Several authors have indicated that the role of perceiving and managing emotions and the sense of meaningfulness has links to wellbeing (Burnett, 2019; Shkoler \& Tziner, 2017; Szczygiel \& Bazinska, 2013). A further exploration of the sense of meaningfulness (sense of coherence) can be regarded as another psychological resource that can spark employees to feel engaged in their work and to find a sense of meaning in remaining in the company (Adil \& Baig, 2018).

This study investigates the interaction effects between call centre agents' emotional intelligence (i.e. managing, utilising and perceiving emotions) and their sense of meaningfulness (as a moderating mechanism) in predicting their exhaustion and professional efficacy.

\section{Method Participants}

The profile of the participants consisted of 409 permanently employed call centre employees in three of the largest outsourced financial call centres in Lagos, Nigeria, and Johannesburg and Durban in South Africa. The participants consisted of $66 \%$ women and $34 \%$ men.

\section{Measures}

Three assessment instruments were used for this study. The Assessing Emotions Scale (AES), developed by Schutte et al. (1998), was used to measure the following four emotional intelligence traits: perceptions of emotion (10 items; e.g. 'I am aware of my emotions'), managing own emotions (9 items; e.g. 'I have control over my emotions'), managing others' emotions ( 8 items; e.g. 'I like to share my emotions with others') and utilisation of emotions (6 items; e.g. 'When my mood changes, I see new possibilities'). Validity studies on the AES have justified the various underlying constructs of the four subscales (Ciarrochi, Chan, \& Caputi, 2000). In terms of reliability (internal consistency), Ciarrochi et al. (2000) reported Cronbach's $\alpha$ coefficient to be 0.55 (moderate) to 0.78 (high).

The Orientation to Life Questionnaire (OLQ) was developed by Antonovsky (1993) to measure meaningfulness (8 items; e.g. 'You anticipate that your personal life in the future will be totally without meaning or purpose versus full of meaning and purpose'). Reliability and validity studies have been empirically tested across different cultures and confirm Cronbach's $\alpha$ ranging from 0.51 to 0.90 . (Eriksson \& Mitelmark, 2017).

The Maslach Burnout Inventory developed by Maslach, Jackson and Leiter (1996) was used to measure the two dimensions of burnout, exhaustion (5 items; e.g. 'Working all day is really a strain for me') and professional efficacy (6 items; e.g. 'I have accomplished many worthwhile things in this job'). Reliability studies have shown the MBI to have Cronbach's $\alpha$ ranging from 0.70 to 0.80 (Edwards et al., 1997).

\section{Ethical consideration}

The study has been carried out strictly in accordance with the Policy for Research Ethics of the University of South Africa (UNISA) and ethical clearance was obtained from the University Research Ethics committee. The author took great care that the research was conducted with the highest integrity, taking into account UNISA's Policy for Infringement and Plagiarism. The human resource manager of the call centres in Africa granted permission to conduct the research study. Each questionnaire included a covering letter inviting the respondents to participate voluntarily in the study and 
assuring them that their individual responses would remain anonymous and confidential. After 500 questionnaires were sent out, the research procedure yielded 409 useable questionnaires (response rate $=82 \%$ ).

\section{Analysis}

Moderated regression analysis, applying the Hayes PROCESS procedure (Hayes, 2018), was used to achieve the research aim. The more stringent, bias-corrected bootstrapping technique (Hayes, 2018) with the 95\% lower level (LLCI) and upper level (ULCI) range not including zero, was used to examine the significance of the interaction effects. Cohen's $f^{2}$ was used to assess the practical effect of significant interaction effects.

\section{Results \\ Descriptive statistics}

Table 1 presents the means, standard deviations, internal reliability coefficients of the variables and bi-variate correlations.

As shown in Table 1, the internal consistency reliability for the scales ranged between $(>0.61$ and $>0.87$ ). The bivariate correlations between meaningfulness and utilising emotions, perceptions of emotions and managing emotions variables ranged between $r \geq 0.18$ and $r \leq 0.79$ ( $p \leq 0.01$; small practical effect) suggesting that multicollinearity was not a threat to the findings $(r<0.80)$. The exhaustion variable negatively correlated with meaningfulness, utilising emotions, perceptions of emotions and managing emotions ( $r \geq-0.12$ and $r \leq-0.38)$.

Professional efficacy variable correlated positively with meaningfulness, utilising emotions, perceptions of emotions and managing emotions $(r \geq 0.12$ and $r \leq 0.30)$.

\section{Moderated regression analysis}

Table 2 presents moderated regression analysis. Four models with a more stringent bootstrapping approach (Hayes, 2018) were used. Model 1, comprising of three variables: managing others' emotions moderated by sense of meaningfulness in predicting exhaustion; Model 2, comprising of three variables: utilising emotions moderated by sense of meaningfulness in predicting exhaustion; Model 3, comprising of three variables: perceptions of emotions moderated by sense of meaningfulness in predicting exhaustion; Model 4, comprising of three variables: managing own emotions moderated by sense of meaningfulness in predicting exhaustion.

According to Table 2, only two regression models were significant: Model 1, $F_{p}=28.198, p=0.001$ and Model 3, $F_{p}=$ $27.542, p=0.001$. The adjusted $R^{2}$ ranged between 0.16 and 0.17 (moderate practical effect).

Significant interaction effects were only observed in terms of Model 1 (managing others' emotions x meaningfulness: $\beta=-0.40 ;$ LLCI $=-0.63 ;$ ULCI $=-0.16 ; p=0.01 ; f^{2}=10.58$ (small practical effect) and Model 3 (perceptions of emotions $\mathrm{x}$ meaningfulness: $\beta=-0.45 ; \mathrm{LLCI}=-0.72 ; \mathrm{ULCI}=-0.19$; $p=0.001 ; f^{2}=11.32$ (small practical effect). Figures 1 and 2 illustrate the interaction effects.

Figure 1 displays the interaction effect, that is managing others' emotions $x$ sense of meaningfulness in predicting exhaustion, shows that the participants high on managing others' emotions and high sense of meaningfulness experienced significantly lower levels of exhaustion than those who had low levels of managing others' emotions and sense of meaningfulness. Those participants who had a significantly low sense of meaningfulness also had a significantly high level of exhaustion irrespective of their high level of managing others' emotions.

Figure 2 displays the interaction effect, that is perceptions of emotions $x$ sense of meaningfulness in predicting exhaustion, shows that the participants high on perceptions of emotions and high sense of meaningfulness experienced significantly lower levels of exhaustion than those who had low levels of perceptions of emotions and sense of meaningfulness. Those participants who had a significantly low sense of meaningfulness also had a significantly high level of exhaustion irrespective of their high level of perceptions of emotions.

Table 3 presents moderated regression analysis. Four models with a more stringent bootstrapping approach (Hayes, 2018) were used. Model 1, comprising of three variables: managing others' emotions moderated by sense of meaningfulness in predicting professional efficacy; Model 2, comprising of three variables: utilising emotions moderated by sense of meaningfulness in predicting professional efficacy; Model 3, comprising of three variables: perceptions of emotions moderated by sense of meaningfulness in predicting professional efficacy; Model 4, comprising of three variables:

TABLE 1: Descriptive statistics and bi-variate correlations $(N=409)$.

\begin{tabular}{|c|c|c|c|c|c|c|c|c|c|}
\hline Variable & M & SD & $\alpha$ & 1 & 2 & 3 & 4 & 5 & 6 \\
\hline 1. Meaningfulness & 4.92 & 1.10 & 0.71 & 1 & - & - & - & - & - \\
\hline 2. Utilising emotions & 4.13 & 0.59 & 0.61 & $0.60 * * *$ & 1 & - & - & - & - \\
\hline 3. Perceptions of emotions & 3.73 & 0.53 & 0.64 & $0.79 * * *$ & $0.18^{*}$ & 1 & - & - & - \\
\hline 4. Managing own emotions & 4.30 & 0.56 & 0.73 & $0.53 * * *$ & $0.55 * * *$ & $0.65 * * *$ & 1 & - & - \\
\hline 5. Exhaustion & 2.93 & 1.74 & 0.87 & $-0.38 *$ & $-0.15^{*}$ & $-0.12^{*}$ & $-0.27 *$ & 1 & - \\
\hline 6. Professional efficacy & 4.84 & 1.038 & 0.73 & $0.30 * *$ & $0.20 *$ & $0.12 *$ & $0.26 *$ & 0.048 & 1 \\
\hline
\end{tabular}

$\mathrm{M}$, mean; SD, standard deviation

$*, p \leq 0.05 ; * *, p \leq 0.01 ; * * *, p \leq 0.001$. 
TABLE 2: Moderated regression results: Managing others' emotions, utilising emotions, perceptions of emotions, managing own emotions moderated by sense of meaningfulness in predicting exhaustion $(N=409)$.

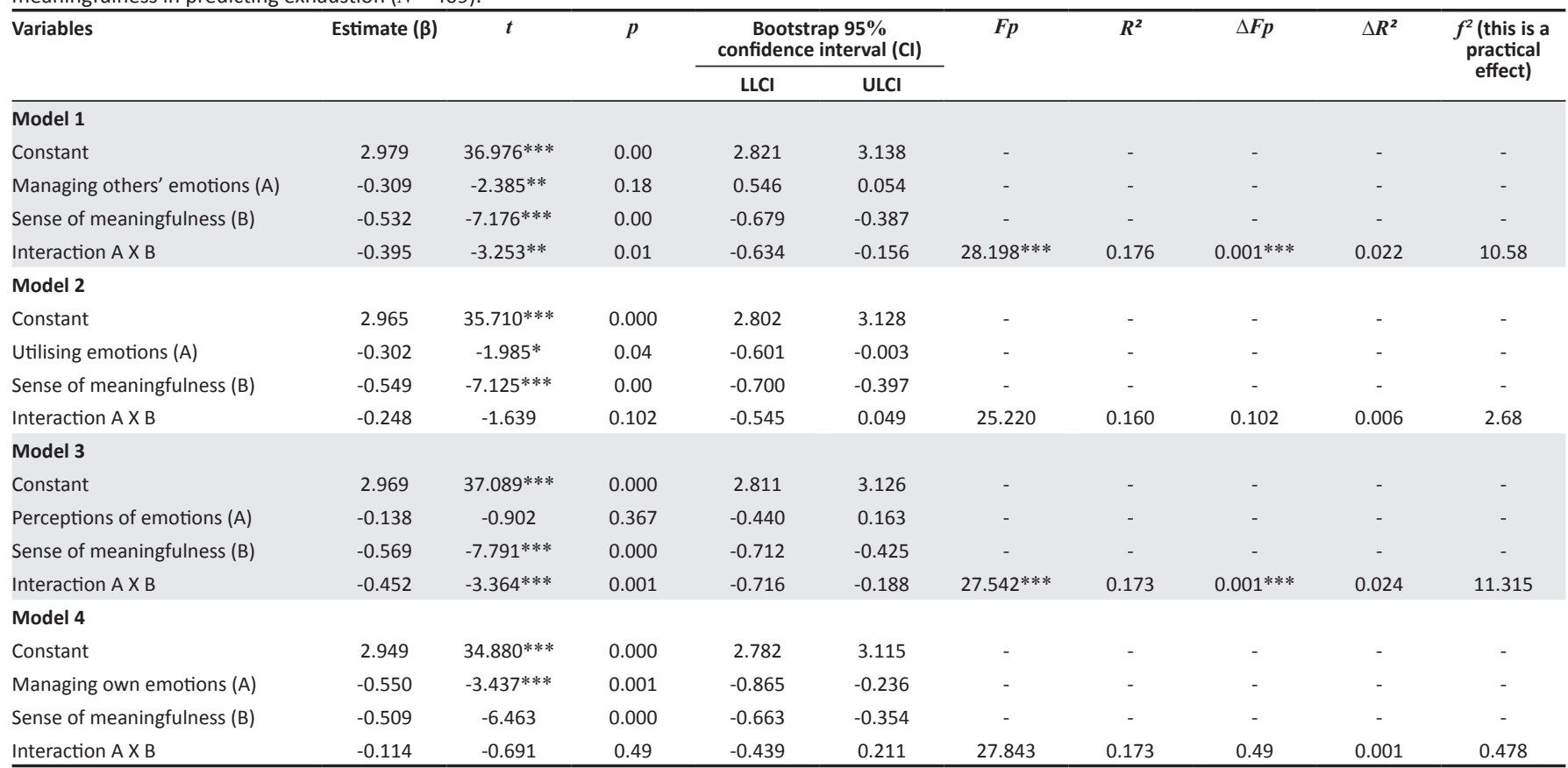

$\mathrm{SE}$, standard error; LLCI, lower limit confidence interval; ULCI, upper limit confidence interval.

$*, p<0.01 .95 \% \mathrm{BC} \mathrm{Cl}: 95 \%$ bias corrected confidence interval; ***, $p \leq 0.001 ; * *, p \leq 0.01 ; *, p \leq 0.05$.

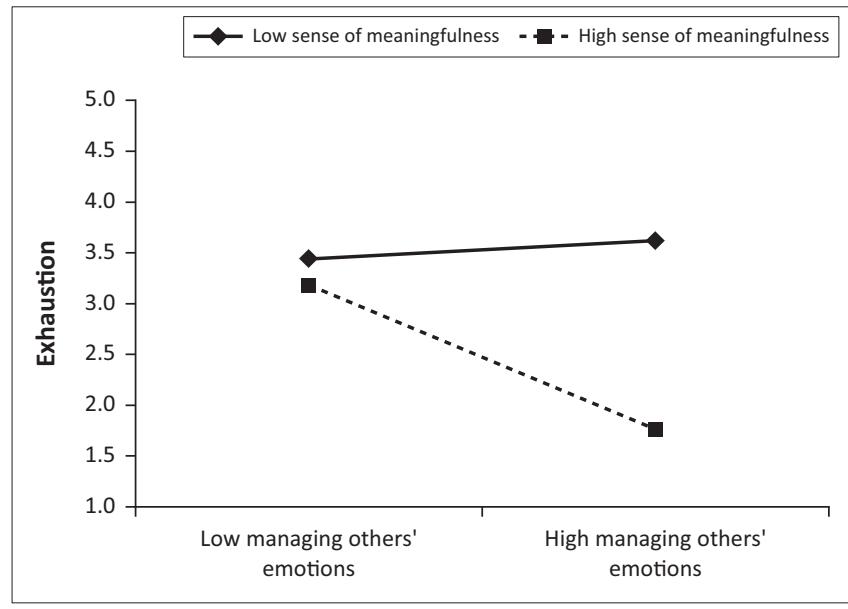

FIGURE 1: Interaction effect (managing others' emotions $x$ sense of meaningfulness) in predicting exhaustion.

managing own emotions moderated by sense of meaningfulness in predicting professional efficacy.

According to Table 3, only two regression models were significant: Model 1: $F_{p}=24.59, p=0.035$ and Model 3: $F_{p}=17.078, p=0.013$. The adjusted $R^{2}$ ranged between 0.11 and 0.17 (moderate practical effect). Significant interaction effects were only observed in terms of Model 1 (managing others' emotions $x$ meaningfulness: $\beta=-0.16$; LLCI $=-0.30$; $\mathrm{ULCI}=-0.01 ; p=0.04 ; f^{2}=4.47$ (small practical effect) and Model 3 (perceptions of emotions $x$ meaningfulness: $\beta=-0.21 ; \mathrm{LLCI}=-0.37 ; \mathrm{ULCI}=-0.04 ; p=0.01 ; f^{2}=6.25$, $(\mathrm{small}$ practical effect). Figures 3 and 4 illustrate the interaction effects.

Figure 3 displays the interaction effect, that is managing others' emotions $x$ sense of meaningfulness in predicting

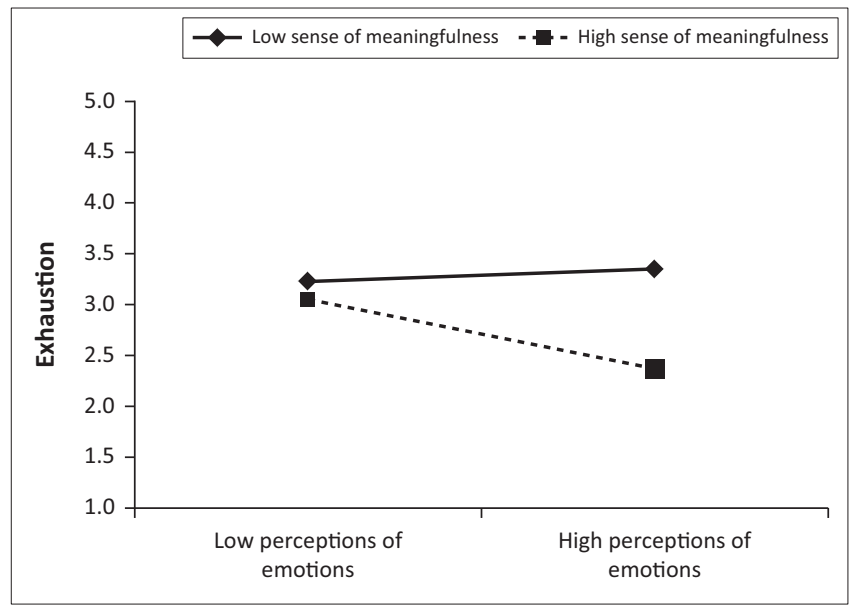

FIGURE 2: Interaction effect (perceptions of emotions $x$ sense of meaningfulness) in predicting exhaustion.

professional efficacy, shows that the participants low on managing others' emotions and with a low sense of meaningfulness experienced significantly lower levels of professional efficacy than those who had high levels of managing others' emotions and a high sense of meaningfulness. Those participants who had high levels of managing others' emotions and a significantly high sense of meaningfulness also experienced higher levels of professional efficacy than those with a lower sense of meaningfulness.

Figure 4 displays the interaction effect, that is perceptions of emotions $x$ sense of meaningfulness in predicting professional efficacy, shows that the participants low on perceptions of emotions and with a low sense of meaningfulness experienced significantly lower levels of professional efficacy than those who had high levels of managing others' emotions and a 
TABLE 3: Moderated regression results: Managing others' emotions, utilising emotions, perceptions of emotions, managing own emotions moderated by sense of meaningfulness in predicting professional efficacy $(N=409)$.

\begin{tabular}{|c|c|c|c|c|c|c|c|c|c|c|}
\hline \multirow[t]{2}{*}{ Variables } & \multirow[t]{2}{*}{$\underset{(\beta)}{\text { Estimate }}$} & \multirow[t]{2}{*}{$t$} & \multirow[t]{2}{*}{$p$} & \multicolumn{2}{|c|}{$\begin{array}{c}\text { Bootstrap 95\% } \\
\text { confidence interval (CI) }\end{array}$} & \multirow[t]{2}{*}{$F p$} & \multirow[t]{2}{*}{$R^{2}$} & \multirow[t]{2}{*}{$\Delta F p$} & \multirow[t]{2}{*}{$\Delta R^{2}$} & \multirow{2}{*}{$\begin{array}{c}f^{2} \text { (this is } \\
\text { practical } \\
\text { effect) }\end{array}$} \\
\hline & & & & LLCl & ULCI & & & & & \\
\hline \multicolumn{11}{|l|}{ Model 1} \\
\hline Constant & 4.872 & $99.703 * * *$ & 0.000 & 4.776 & 4.968 & - & - & - & - & - \\
\hline Managing others' emotions(A) & 0.327 & $4.179 * * *$ & 0.000 & 0.173 & 0.481 & - & - & - & - & - \\
\hline Sense of meaningfulness(B) & 0.270 & $5.983 * * *$ & 0.000 & 0.181 & 0.358 & - & - & - & - & - \\
\hline Interaction A X B & -0.156 & $-2.116 *$ & 0.035 & -0.300 & -0.011 & $24.59 * * *$ & 0.157 & 0.035 & 0.010 & 4.47 \\
\hline \multicolumn{11}{|l|}{ Model 2} \\
\hline Constant & 4.864 & $95.363 * * *$ & 0.000 & 4.763 & 4.964 & - & - & - & - & - \\
\hline Utilising emotions (A) & 0.229 & $2.452 * *$ & 0.015 & 0.045 & 0.412 & - & - & - & - & - \\
\hline Sense of meaningfulness(B) & 0.275 & $5.797 * * *$ & 0.000 & 0.181 & 0.368 & - & - & - & - & - \\
\hline Interaction A X B & -0.086 & -0.930 & 0.353 & -0.269 & 0.096 & 17.982 & 0.120 & 0.353 & 0.002 & 0.865 \\
\hline \multicolumn{11}{|l|}{ Model 3} \\
\hline Constant & 4.870 & $97.740 * * *$ & 0.000 & 4.772 & 4.968 & - & - & - & - & - \\
\hline Sense of meaningfulness(B) & 0.289 & $6.346 * * *$ & 0.000 & 0.200 & 0.379 & - & - & - & - & - \\
\hline Interaction A X B & -0.209 & $-2.499 * *$ & 0.013 & -0.373 & -0.044 & $17.078^{* * *}$ & 0.115 & 0.013 & 0.014 & 6.246 \\
\hline \multicolumn{11}{|l|}{ Model 4} \\
\hline Constant & 2.677 & $36.379 * * *$ & 0.000 & 2.485 & 2.769 & - & - & - & - & - \\
\hline Managing own emotions & -0.172 & $-1.507^{*}$ & 0.133 & -1.395 & 0.052 & - & - & - & - & - \\
\hline Sense of meaningfulness(B) & -0.104 & $-1.275^{*}$ & 0.203 & -0.263 & 0.056 & - & - & - & - & - \\
\hline Interaction A X B & 0.119 & 1.052 & 0.293 & -1.103 & 0.342 & 2.237 & 0.017 & 0.293 & 0.003 & 1.107 \\
\hline
\end{tabular}

$\mathrm{SE}$, standard error; $\mathrm{LLCl}$, lower limit confidence interval; ULCI, upper limit confidence interval.

$*, p<0.01 .95 \% \mathrm{BCCl}, 95 \%$ bias corrected confidence interval; ***, $p \leq 0.001 ; * *, p \leq 0.01 ; *, p \leq 0.05$.

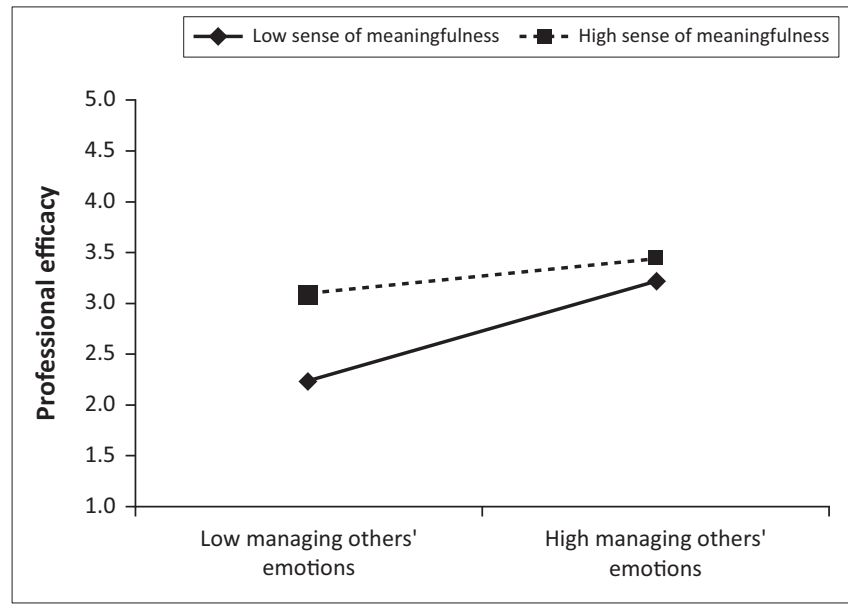

FIGURE 3: Interaction effect (managing others' emotions $x$ sense of meaningfulness) in predicting professional efficacy.

high sense of meaningfulness. Those participants who had high levels of perceptions of emotions and a significantly high sense of meaningfulness also experienced higher levels of professional efficacy than those with a lower sense of meaningfulness.

\section{Discussion}

The objective of the study was to investigate the interaction effects between call centre agents' emotional intelligence (i.e. managing, utilising and perceiving emotions) and their sense of meaningfulness (as moderating mechanism) in predicting their exhaustion and professional efficacy. The findings of the slope analysis in Figures 1 and 2 suggest that high sense of meaningfulness strengthens individuals' managing others' emotions and perceptions of emotions which in turn reduce exhaustion. The role of meaningfulness, which is regarded as

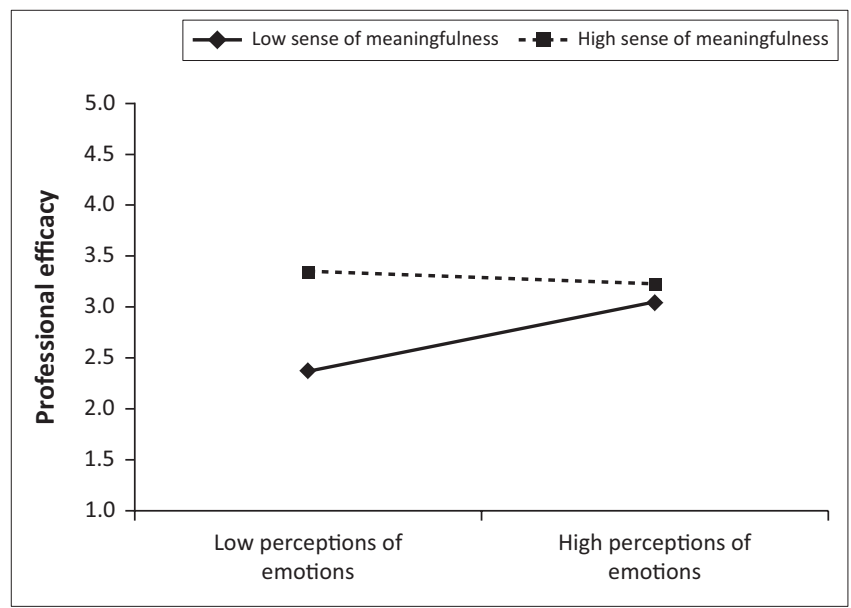

FIGURE 4: Interaction effect (perceptions of emotions $x$ sense of meaningfulness) in predicting exhaustion.

a motivational aspect of sense of coherence represents the belief and the extent to which an individual wishes to cope based on the conviction of having sufficient resources to successfully face the demands of the world.

Motivation is derived from a person's internal world which can be regarded as an internal psychological resource where call centre agents will participate in shaping outcomes thereby creating sense of meaningfulness in their work environments (Hochwälder, 2019).

Individuals recognise the ability to monitor other employees' emotions and use this emotional information to guide thinking, behaviour and performance within call centres, which has been highlighted by several authors (Goleman, 1995; Mayer \& Salovey, 1997; Salovey \& Mayer, 1990; Shkoler 
\& Tztner, 2017). Research also indicates that having good perceptions of emotions is an important factor in maintaining health as employees will display meaningfulness in the work they do (Pulido-Martos et al., 2016; Yin et al., 2013). The results extracted from research show that in call centres in Africa, higher perceptions of emotions brings optimal satisfaction, contributing to better self-esteem (Ghanizadeh \& Royaei, 2015; Zysberg et al., 2017), affirming that a person's perceptions of emotions and meaningfulness do play a role in call centres in Africa (Hochwälder, 2019; Van der Westhuizen, 2018).

Employees in call centres may not turn to work misbehaviour; they will regulate their emotions and create a balance by means of self-regulation and self-control as indicated in research (Sckoler \& Tztner, 2017). This suggests that when employees are confronted with an affective stimulus derived from an individual's internal world, he/she will constitute an understanding of their emotions and guide their thinking into coping with the stressors as highlighted in research (Aderibigbe, \& Mjoli, 2019; Görgens-Ekermans, \& Brand, 2012; Mérida-López, Extremera, Quintana-Orts, \& Rey, 2019; Sckoler \& Tztner, 2017).

The findings of the slope analysis in Figures 1 and 2 also suggest a reduced sense of meaningfulness can lead to lack of managing others' emotions and perceptions of emotions, which in turn increases exhaustion. Research into call centres proves that when employees reach a point of extreme tiredness, they act to conserve the level of energy and regulate these resources by reducing their cognitive and emotional involvement in their work and withdraw (Montalbo, 2016). Research on call centre agents reveals a high level of emotional exhaustion leading to a sharp increase in cynicism and an experience of low professional efficacy, resulting from a lack of soft skills required to handle emotional stress (Montalbo, 2016). A reduced sense of meaningfulness results when emotional meaning in a person's life is magnified. This in turn may result in problems of resolving difficulties, and the willingness to invest energy to get through experiences of stress-causing distress (Eriksson \& Mittelmark, 2017).

The findings of the slope in Figures 3 and 4 suggest that those individuals, with a lower sense of meaningfulness and managing others' emotions and perceptions of emotion, have reduced levels of professional efficacy. In research, it has been revealed that when the demands in an environment become high then the sense of meaningfulness gets eroded with time (Bachem \& Maercker, 2016; Gärtner, Behnke, Conrad, Kolassa, \& Rojas, 2019; Veronese, \& Pepe, 2017). This behavioural mechanism gives people the opportunity to use their internal resources in stressful times. Certain conditions change individuals with time, as a result, individuals will try and achieve a coherent whole that includes the good and the bad (Bachem \& Maercker, 2016; (Gärtner et al., 2019). Research indicates that call centres report low scores in professional efficacy when call centre agents feel that they cannot handle the task, experience feelings of incompetence, lack of achievement and lower productivity (Montalbo, 2016).

The results also suggest that those individuals with a high sense of meaningfulness, managing others' emotions and perceptions of emotions, have increased levels of professional efficacy. Through research, it is established that one's internal and external environment is predictive of an individual's high sense of meaningfulness (Eriksson \& Mittelmark, 2017). This is coupled with the notion that stressors are meaningful and deserve to be handled with concern (Eriksson \& Mittelmark, 2017). Researches on call centres have proven that increased levels of professional efficacy are the result of personal resources that individuals possess relating to resiliency and self-esteem (Harry, 2015; Glück, Tran, Raninger, \& Lueger-Schuster, 2016; Györkös, Geldenhuys, Massoudi, \& Rossier, 2013). The psychological resources of individuals associated with sustained cognitive and emotional skills are required to function to achieve goals, reduce job demands and stimulate personal growth (Janse van Rensburg, Boonzaier, \& Boonzaier, 2013). Research suggests emotional and social competencies such as knowledge, motives, attributes and skills are causally related to affective performance. Workers develop an inventory of emotional competencies such as managing others' emotions and perceptions of emotions that together relate to a higher order of emotional intelligence (Goleman, 1995; Mayer \& Salovey, 1997; Salovey \& Mayer, 1990; Shkoler \& Tztner, 2017; Szczygiel, \& Mikolajczak, 2018).

\section{Practical implications for wellness programmes}

Interventions to develop sense of meaningfulness, managing others' emotions and perceptions of emotions may help to reduce levels of exhaustion and increase professional efficacy in the call centre industry. The research suggests that sense of meaningfulness, managing others' emotions and perceptions of emotions as an important wellbeing variable when improving the wellness of call centre agents in Africa.

\section{Limitations}

This study could not generalise the findings to other occupational contexts as it was confined to the call centre work environment only with a sample of predominantly of single, employed black females. The self-reporting approach was followed and the association between the variables could also have been influenced by common method variance. Though, self-reports were probably the most accurate means as they involved internal psychological processes.

\section{Conclusion}

The study confirmed the objective that investigated the interaction effects between call centre agents' emotional intelligence (i.e. managing, utilising and perceiving emotions) and their sense of meaningfulness (as moderating mechanism) 
in predicting their exhaustion and professional efficacy. Overall the results provide evidence of the importance of considering the call centre agent's sense of meaningfulness, managing others' emotions and perceptions of emotions can significantly lower levels of exhaustion and increase professional efficacy. Individuals low on sense of meaningfulness as an outcome variable, managing others' emotions and perceptions of emotions can significantly increase exhaustion levels and lower professional efficacy.

Interventions based on empowerment and reflection processes can fuel further development of sense of meaningfulness that can underpin health promotion activities in call centres in Africa.

\section{Acknowledgements Competing interests}

The author declares that she has no financial or personal relationships that may have inappropriately influenced her in writing this research article.

\section{Author's contribution}

N.H. is the sole author of this research article.

\section{Funding information}

This research received no specific grant from any funding agency in the public, commercial, or not-for-profit sectors.

\section{Data availability}

Data sharing is not applicable to this article as no new data were created or analysed in this study.

\section{Disclaimer}

The views and opinions expressed in this article are those of the author and do not necessarily reflect the official policy or position of any affiliated agency of the author.

\section{References}

Aderibigbe, J.K., \& Mjoli, T.Q. (2019). Emotional intelligence as a moderator in the relationship between occupational stress and organizational citizenship behavio among Nigerian graduate employees. Journal of Economics and Behavioral Studies, 10(6A), 152-163. https://doi.org/10.22610/jebs.v10i6A.2671

Adil, M.S., \& Baig, M. (2018). Impact of job demands-resources model on burnout and employee's well-being: Evidence from the pharmaceutical organisations of Karachi. IIMB Management Review, 30(2), 119-133. https://doi.org/10.1016/j iimb.2018.01.004

Antonovsky, A. (1993). The structure and properties of the Sense of Coherence Scale. Social Science and Medicine, 36, 725-733. https://doi.org/10.1016/02779536(93)90033-Z

Anwar, M.A., \& Graham, M. (2019). Does economic upgrading lead to social upgrading in contact centers? Evidence from South Africa. African Geographical Review, 38(3), 209-226. https://doi.org/10.1080/19376812.2019.1589730

Bachem, R., \& Maercker, A. (2016). Development and psychometric evaluation of a revised Sense of Coherence Scale. European Journal of Psychological Assessment, 34(3), 206-215. https://doi.org/10.1027/1015-5759/a000323

Boyatzis, R.E. (2009). Competencies as a behavioral approach to emotional intelligence [Editorial]. Journal of Management Development, 28(9), 749-770. https://doi. org/10.1108/02621710910987647

Burnett, S.R. (2019). Employee engagement and burnout: A quantitative study of their correlations with job/organisational satisfaction. Unpublished Doctorate Dissertation. San Diego, CA: University of San Diego.
Ciarrochi, J.V., Chan, A.Y.C., \& Caputi, P. (2000). A critical evaluation of the emotional intelligence construct. Personality and Individual Differences, 28(3), 539-561. $\mathrm{https}$ ://doi.org/10.1016/S0191-8869(99)00119-1

Edwards, N., Sims-Jones, N., Hotz, S., \& Cushman, R. (1997). Development and testing components of a multifaceted intervention program to reduce the incidence of smoking relapse during pregnancy and post-partum of both women and their partners. Report prepared for Health Canada at the Community Health Research partners. Report prepared for Health
Unit, University of Ottawa, Canada.

Eriksson, M. \& Mittelmark, M.B. (2017). The sense of coherence and its measurement. In M.B. Mittelmark, S. Sagy, M. Eriksson, G.F. Bauer, J.M. Pelikan, B. Lindström, et al. (Eds.), Handbook of salutogenesis (pp. 97-105). Berlin: Springer.

Frost, A., \& Sullivan, E. (2018). Customer contact executive MindXchange. Paper presented at the 14th Annual Customer contact MindXchange Conference, 2018. Fort Lauderdale Marriott Harbor Beach Resort \& Spa, Fort Lauderdale, FL.

Gärtner, A., Behnke, A., Conrad, D., Kolassa, I.-T., \& Rojas, R. (2019). Emotion regulation in rescue workers: Differential relationship with perceived work-related stress and stress-related symptoms. Frontiers in Psychology, 9, 2744. https://doi.org/ stress-related symptoms.
$10.3389 /$ fpsyg.2018.02744

Ghanizadeh, A., \& Royaei, N. (2015). Emotional facet of language teaching: emotion regulation and emotional labor strategies as predictors of teacher burnout. International Journal of Pedagogies and Learning, 10(2), 139-150. https://doi.org/10.1080/22040552.2015.1113847

Glück, T.M., Tran, U.S., Raninger, S., \& Lueger-Schuster, B. (2016). The influence of sense of coherence and mindfulness on PTSD symptoms and posttraumatic cognitions in a sample of elderly Austrian survivors of World War II. Internationa cognitions in a sample of elderly Austrian survivors of World War II. International
Psychogeriatrics, 28(3), 435-441. https://doi.org/10.1017/S104161021500143X

Goleman, D. (1995). Emotional intelligence: Why it can matter more than IQ. New York, NY: Bantam Books.

Görgens-Ekermans, G., \& Brand, T. (2012). Emotional intelligence as a moderator in the stress-burnout relationship: A questionnaire study on nurses. Journal of Clinical Nursing, 21(15-16), 2275-2285. https://doi.org/10.1111/j.1365-2702.2012.04171.x

Györkös, C., Geldenhuys, M., Massoudi, K., \& Rossier, J. (2013). Sense of coherence and job characteristics in predicting burnout in a South African sample. SA Journal of Industrial Psychology/SA Tydskrif vir Bedryfsielkunde, 39(1), Art. \#1096, 9 pages. https://doi.org/10.4102/sajip.v39i1.1096

Hanafi, A. (2016). The effect of emotional intelligence on burnout and the impact on the nurses service quality. Journal of Economics, Business and Accountancy Ventura, 19(1), 69. https://doi.org/10.14414/jebav.v19i1.530

Harry, N. (2015). Constructing a psychological coping profile for call centre agents. Unpublished Doctorate Dissertation. Pretoria; University of South Africa.

Hayes, A.F. (2018). Introduction to mediation, moderation, and conditional process analysis: A regression-based approach (2nd edn.). New York, NY: The Guilford Press.

Hochwälder, J. (2019). Sense of coherence: Notes on some challenges for future research. Sage Open, 9, 1-8. https://doi.org/10.1177/2158244019846687

Janse van Rensburg, Y., Boonzaier, B., \& Boonzaier, M. (2013). The job demands resources model of work engagement in South African call centres. SA Journal of Human Resource Management, 11(1), Art. \#484, 13 pages. https://doi.org/ 10.4102/sajhrm.v11i1.484

Johnston, C.S., De Bruin, G.P., Györkös, C., Geldenhuys, M., Massoudi, K., \& Rossier, J. (2013). Sense of coherence and job characteristics in predicting burnout in a South African sample. SA Journal of Industrial Psychology, 39(1), a1096. https:// doi.org/10.4102/sajip.v39i1.1096

Joseph, D.L., \& Newman, D.A. (2010). Emotional intelligence: An integrative metaanalysis and cascading model. Journal of Applied Psychology, 95(1), 54-78. https://doi.org/10.1037/a0017286

Ma, J., \& Liu, C. (2019). The moderating effect of emotional intelligence on the relationship between supervisor conflict and employees' counterproductive work behaviors. International Journal of Conflict Management, 30(2), 227-245. https:// doi.org/10.1108/IJCMA-11-2017-0140

Maslach, C., Jackson, S.E., \& Leiter, M.P. (1996). Maslach burnout inventory manual. Palo Alto, CA: Consulting Psychologists Press.

Mayer, J.D., \& Salovey, P. (1997). What is emotional intelligence? In P. Salovey \& D.J. Sluyter (Eds.), Emotional development and emotional intelligence: Educational implications (pp. 3-34). San Diego, CA: Basic Books.

Mérida-López, S., Extremera, N., Quintana-Orts, C., \& Rey, L. (2019). Does emotional intelligence matter in tough times? A moderated Mediation Model for explaining health and suicide risk amongst short- and long-term unemployed adults. Journa of Clinical Medicine, 8(6), 797. https://doi.org/10.3390/jcm8060797

Montalbo, A. (2016). The burnout level of call center agents in Metro Manila, Philippines. International Letters of Social and Humanistic Sciences, 70, 21-29. https://doi.org/10.18052/www.scipress.com/ILSHS.70.21

Por, J., Barriball, L., Fitzpatrick, J.M., \& Roberts, J. (2011). Emotional intelligence: Its relationship to stress, coping, well-being and professional performance in nursing students. Nurse Education Today, 31(8), 855-860. https://doi.org/10.1016/j. nedi.2010.12.023

Pulido-Martos, M., Lopez-Zafra, E., Estévez-López, F., \& Augusto-Landa, J.M. (2016). The moderator role of perceived emotional intelligence in the relationship between sources of stress and mental health in teachers. The Spanish Journal of Psychology, 19, E7. https://doi.org/10.1017/sjp.2016.8

Richardson, C., \& Ratner, P. (2006). Sense of coherence as a moderator of the effects of stressful life events on health. American Journal of Epidemiology, 163(suppl_11), S210-S210. https://doi.org/10.1093/aje/163.suppl_11.S210-c. 
Rohani, C., Abedi, H.A., Sundberg, K., \& Langius-Eklöf, A. (2015). Sense of coherence as a mediator of health-related quality of life dimensions in patients with breast cancer: a longitudinal study with prospective design. Health and
Outcomes, 13, 195. https://doi.org/10.1186/s12955-015-0392-4

Salovey, P., \& Mayer, J.D. (1989-1990). Emotional intelligence. Imagination, Cognition and Personality, 9(3), 185-211. https://doi.org/10.2190/DUGG-P24E-52WK-6CDG

Schäfer, S.K., Becker, N., King, L., Horsch, A., \& Michael, T. (2019). The relationship between sense of coherence and post-traumatic stress: A meta-analysis. European 98.2018.1562839

Schutte, N.S., Malouff, J.M., Hall, L.E., Haggerty, D.J., Cooper, J.T., Golden, C.J., \& Dornheim, L. (1998). Development and validation of a measure of emotional intelligence. Personality and Individual Differences, 25(2), 167-177. https://doi. org/10.1016/S0191-8869(98)00001-4

Shkoler, O., \& Tziner, A. (2017). The mediating and moderating role of burnout and emotional intelligence in the relationship between organizational justice and work misbehavior. Journal of Work and Organization
157-164. http://dx.doi.org/10.1016/j.rpto.2017.05.002

Szczygiel, D., \& Bazinska, R. (2013). Emotional intelligence as a moderator in the relationship between negative emotions and emotional exhaustion amon employees in service sector occupations. Polish Psychological Bulletin, 44(2), 201-212. https://doi.org/10.2478/ppb-2013-0023

Szczygiel, D.D., \& Mikolajczak, M. (2018). Emotional intelligence buffers the effects of negative emotions on job burnout in nursing. Frontiers in Psychology, 9, 2649. negative emotions on job burnout in nursing
https://doi.org/10.3389/fpsyg.2018.02649
Teinlin, C., Dölitzsch, C., Kind, N., Fischer, S., Schmeck, K., Fegert, J.M., \& Schmid, M. (2017). The influence of sense of coherence, self-care and work satisfaction on secondary traumatic stress and burnout among child and youth residential care workers in Switzerland. Child \& Youth Services, 38(2), 159-175. https://doi.org/ 10.1080/0145935X.2017.1297225

Van der Westhuizen, S.C. (2018). Incremental validity of work-related sense of coherence in predicting work wellness. SA Journal of Industrial Psychology, 44, 1467. https://doi.org/10.4102/sajip.v44i0.1467

Veronese, G., \& Pepe, A. (2017). Sense of coherence as a determinant of psychological well-being across professional groups of aid workers exposed to war trauma. Journal of Interpersonal Violence, 32(13), 1899-1920. https://doi. org/10.1177/0886260515590125

Yin, R.K. (2013). Case study research: Design and methods. 5th edn. UK: SAGE Publication.

Zerach, G., \& Levin, Y. (2018). Posttraumatic stress symptoms, burn-out, and compassion satisfaction among body handlers: The mediating role of sense of coherence and spirituality at workplace. Journal of Interpersonal Violence, 33(12), 1931-1957. https://doi.org/10.1177/0886260515621065

Zysberg, L., Orenshtein, C., Gimmon, E., \& Robinson, R. (2017). Emotional Intelligence, personality, stress, and burnout among educators. International Journal of Stress Management, 24(Suppl 1), 122-136. https://doi.org/10.1037/ str0000028 